chado Reynaldos, cuenta luego a Venus sus andanzas por la corte y predice por fin a unos rústicos su ventura amorosa en forma de enigmas:

$$
\begin{aligned}
& \text { Tú, Lauso, jamás serás } \\
& \text { desechado, ni admitido; } \\
& \text { la pa. . . . . . . . . . . . . } \\
& \text { suplicaráa a quien le ruega. } \\
& \text { Y esto dicho, el fin se llega } \\
& \text { de dar fin a esta jornada. }
\end{aligned}
$$

Un examen entre las obras de Torres Naharro, Juan de la Cueva, Cervantes, Lope, Tirso y Alarcón, revela que no hay actos intermedios que contengan la palabra jornada en sus versos finales, cuyo anuncio habría roto la continuidad de la ilusión muy inoportunamente, aunque a veces el gracioso lo hiciera con sus intromisiones crítico-realistas ${ }^{4}$. Sería, pues, excepcional este supuesto fin de jornada (fin de acto), con frase olvidada luego en una supuesta prolongación. Pero los versos que siguen al parlamento de Amor denuncian a las claras que se trata de un 'viaje', no de un 'acto':

$$
\begin{aligned}
& \text { Lauso.-En tanto, Amor, que te vas, } \\
& \text { porque algún contento goces, } \\
& \text { de nuestras rústicas voces } \\
& \text { el rústico acento oirás. }
\end{aligned}
$$

Los rústicos cantan, y mientras cantan, se va el carro de Venus, y Cupido en él, y suenan las chirimías, y luego dice Lauso:

$$
\begin{aligned}
& \text { Vamos a nuestras cabañas } \\
& \text { a hacer nuestras alegrías, } \\
& \text { etc. (pág. 277). }
\end{aligned}
$$

The University of Southern California.

Joseph Silverman

\title{
SOBRE PEDRO MEXÍA EN INGLATERRA
}

\section{I}

Varias fuentes se han sugerido, en los últimos años, para las "siete edades" de Jacques en As you like it de Shakespeare. Entre ellas se encuentran el De proprietatibus rerum de Bartholomaeus Anglicus, que seguramente influyó sobre aquella obra a través de la traducción de Stephen Batman (Batman vppon Bartolome, London, $\left.15^{82}\right)^{\mathrm{I}}$, el De die natali de Catón Censorino y el Onomasticon de Julius Polling ${ }^{3}$. Cada una de

4 C. Bravo-Villasante, La realidad de la ficción, negada por el gracioso, en RFE, XXVIII, I944, págs. 264-268.

1 John W. Draper, Juques" "seven ages" and Bartholomaeus Anglicus, MLN, LIV, 1939, págs. 273-276.

2 Allan H. Gilbert, Jaques" "seven ages" and Censorinus, MLN, LV, I940, págs. I03-105.

3 Josephine W. Bennett, Jaques' seven ages, en The Shakespeare Association Bulletin, XVIII, 1943, págs. I68-173. 
estas fuentes reclama para sí la verdad, y a la discusión ha venido a añadirse el profesor Alien ${ }^{4}$, quien hace algunos años expuso la idea de que la fuente pudo más bien ser la Silva de varia lección de Pedro Mexía, parte I, cap. XLIV": "De las siete edades y partes de la vida del hombre según la doctrina de los astrólogos..." La sugestión parece aún más probable si se considera que no es forzoso suponer que la familiaridad de Shakespeare con el tratamiento que al tema da Mexía se debiera, como aventura el profesor Allen, a un manuscrito del Treasurie de Thomas Milles ${ }^{6}$ que circuló antes de su publicación. En efecto, el capítulo en cuestión apareció traducido en I 57 I en la Foreste de Thomas Fortescue ${ }^{7}$ (cap. xvn de la parte I): Of the distinction of the Age of Man, accordinge to the opinion of moste astrologians ${ }^{8}$. Allibone consideraba que la Foreste debía indiscutiblemente incluirse entre los "Shakspeariana" 9.

Sin embargo, tampoco es forzoso concluir que Shakespeare conociera la Foreste. Una presentación esencialmente idéntica de esas ideas apareció también en I 575, en una compilación de Sir Geoffrey Fenton titulada Golden Epistles, contayning varietie of discourse both Morall, Philosophicall, and Diuine: gathered as well out of the remaynder of Gueuaraes workes, as other Authors, Latine, French, and Italian (London, Henry Middleton, for Rafe Newbery, I 575), en cuatro capítulos, el primero de los cuales, sin número, se titulaba $A$ discourse of the Ages of mans lyfe (ff. I48-I57). El que la compilación de Fenton llevase en la portada el nombre de Guevara, más popular aún en Europa que el de Mexía, así como el título oficial que se solía dar a las Epístolas familiares, puede haber llamado la atención de Shakespeare con más razón que la Foreste, donde, por lo demás, no aparece el nombre de Mexía.

Es imposible probar con certeza que Shakespeare haya recurrido a la enumeración de Fenton-Guevara más bien que a la de Mexía (o a las de Bartholomaeus, Censorino o Pollux); sin embargo, es de notar que, aunque Mexía dice hablar de siete edades, en realidad presenta ocho: la séptima edad lleva al hombre hasta los noventa y ocho años, y "si alguno pasa destos términos el resto de su vida vuelve a tener por su

\footnotetext{
4 Don Cameron Allen, Jacques' "seven ages" and Pedro Mexia, MLN, LVI, I94 I, págs. 60I-603.

5 Allen cita I, XL, refiriéndose a la traducción francesa; la numeración de los capítulos varía hasta en las diversas ediciones españolas. La presente referencia se toma de una edición moderna, la publicada en Madrid por la Sociedad de Bibliófilos Españoles, 2 vols., I933-I934. La Silva se publicó por primera vez en I540; cf. Francisco Escudero y Perosso, Tipografía hispalense, Madrid, I894, págs. I97-198, núm. 408, y Henry Harrisse, Additions a la Bibliotheca Americana Vetustissima, Paris, I 872 , pág. I39, núm. I33.

${ }^{6}$ The Treasurie of auncient and moderne times. Containing the learned Collections, judicious Readings, and memorable Observations ... Translated out of ... Pedro Mexia, and M. Francesco Sansovino... etc., London, W. Jaggard, I6I3-16 I9.

7 The Foreste or Collection of Histories, no lesse profitable, then pleasant and necessarie, dooen out of Frenche into Englishe, by THomas ForTescue, London, Jhon Kyngston, for Willyam Iones, I57I. Esta es una traducción de capítulos selectos de la traducción francesa que Claude Gruget ( $155^{2}$ ) hizo de la Silva.

$8 \mathrm{Ya}$ señalado, en relación con este problema especial, por E. C. Tucker Brooke en The Year's Work in English Studies, XXII, I94 I, pág. Io7.

9 S. Austin Allibone, $A$ critical dictionary of English literature, vol. II, Philadelphia, I87i, pág. 203 I b, núm. 6.
} 
planeta a la Luna, que fué el primero en la edad llamada infancia y niñez. Y así obran los hombres lo que los niños en las condiciones y inclinaciones"10. El punto es importante, porque a la octava subdivisión que hace Mexía, y no a la séptima (la "edad caduca o decrépita"), es a la que corresponde la edad séptima y última de Shakespeare, "... second childishness and mere oblivion, Sans teeth, sans eyes, sans taste, sans every thing". Por otra parte, la enumeración de Fenton rechaza las seis edades de los astrólogos y prefiere las seis edades de San Isidoro. Pero Fenton, como Mexía, especula sobre si la sexta edad debiera dividirse en dos partes, una de las cuales sería la segunda infancia. Aunque luego rechaza la idea, lo hace después de varias páginas de discusión, caracterizadas por una verbosidad monótona y ampulosa, al fin de las cuales el lector queda con la firme impresión de la posible existencia de una séptima edad, que corresponde exactamente a la de Shakespeare ${ }^{11}$.

Pero aún si concediéramos que en este pasaje de Shakespeare hay reminiscencias de la recopilación de Fenton y no de la traducción de la Silva hecha por Fortescue, volvemos a dar inexorablemente, aunque con singular rodeo, a la misma Silva. Los capítulos de que se trata en la colección de Fenton no pertenecen, de hecho, a Antonio de Guevara; fueron traducidos, probablemente de la versión francesa de Antoine du Pynet, quizá de una parte III (parcialmente espuria) de las Lettere de Guevara, publicada ya en ${ } 557$ por Alfonso de Ulloa ${ }^{12}$. Esta parte III contiene traducciones de algunas de las cartas de Guevara (omitidas, por alguna razón, en la traducción italiana de las partes I y II), del Libro de los inventores del marear, y de una serie de cartas y discursos que no se encuentran en ninguna de las obras publicadas de Guevara. Todas estas cosas se tradujeron de un manuscrito inédito, o bien las inventó el mismo Ulloa, cosa que parece más probable ${ }^{13}$. Los cuatro capítulos sobre las edades del hombre están incluidos en este material, y, dadas las semejanzas generales del tema y tratamiento, además de algunas coincidencias textuales, parece casi seguro que esos capítulos, así como el resto del material inventado, provienen de la Silva $a^{14}$.

10 Silva, vol. I, pág. 260.

${ }^{11}$ En principio, me parece inútil buscar en las fuentes algo más que el plan general de las "seven ages" de Jaques. Ocurrencias felices como "the infant, / Mewling and puking in the nurse's arms", parecen ser de Shakespeare sin duda alguna, como anota J. W. Bennett, y es inútil buscarlas en las fuentes.

12 Il terzo libro delle Lettere dell'illustre signor don Antonio di Guevara... nuovamente di lingua spagnola in italiano tradotto per Alfonso di Ulloa, Venezia, V. Valgrisio e B. Constantini, 1557; ejemplar de la Bibliothèque Nationale. En 1560 este libro se tradujo al francés y desde entonces se publicó junto con la traducción del doctor Guterry de los dos primeros libros. Ulloa añadió luego un cuarto libro, y, gracias a ligeras modificaciones que hizo a la traducción original de las partes I y II, debida a Gatzelu, se sintió autorizado a atribuirse la traducción entera. Cf. Eduart Toda y Güell, Bibliografía espanyola d'Italia, 5 vols., Sant Miquel d'Escornalbou, 1927-193 I, vol. II, págs. 235-236.

${ }^{13}$ La cuestión de sí Ulloa falsificó o no estos artículos ha sido discutida extensamente por A. Morel-Fatro, Historiographie de Charles-Quint, Paris, I9I3, págs. 139-143.

${ }^{14}$ Louts Clément, Antoine de Guevara, ses lecteurs et ses imitateurs français au xvi siècle, en Revue d'Histoire Littéraire de la France, VIII, igo1, págs. 2 I62 I7. Sin embargo, Clément, que no consultó las ediciones originales de Guevara, 
En 1943, el profesor Izard señaló ${ }^{15}$ que el Tamburlaine ( $15^{87}$ ) de Marlowe está basado, probablemente, no en el relato de Mexía tal como lo expone Fortescue, sino, con mayor probabilidad, en el de George Whetstone en su English Myrror ${ }^{16}$, libro I, cap. xII, que es traducción abreviada de Mexía, II, xxviII. Esta curiosa observación me llevó a comparar el resto del Myrror con la Silva, y encontré que el cap. Iv del libro I de Whetstone está basado en el libro IV, capítulos xv a xvI de Mexía; el cap. v es una traducción abreviada de I, xxix a xxxi; el cap. vir es abreviación de Mexía, I, xirr; el cap. Ix traduce, con excepción de unas pocas líneas, a Mexía, II, xLV; el cap. XI es traducción abreviada de I, xrv y xv, de Mexía; y el cap. xIv muestra reminiscencias ocasionales de Mexía, IV, xx. En la pág. 36 se cita como autoridad a "Peter Messire", aunque no se hace ningún reconocimiento general de la utilización de su obra. Por más que el método de Whetstone implicaba grandes cortes del texto original, y la adición de datos suplementarios, particularmente de observaciones moralizadoras, el material que eligió sigue al original con bastante fidelidad, y se puede considerar el English Myrror como otro testimonio importante de la extraordinaria popularidad de que disfrutó por espacio de más de un siglo la Silva de varia lección del magnífico caballero.

Harvard University.

Philip A. Turner

\section{DOS NOTAS SOBRE EL INGA GARGILASO}

\section{I}

\section{Aldrete y EL INGA}

Entre fines del xvi y principios del xvII, tres varones insignes de las letras españolas concurren a la vieja catedral de Córdoba. Un poeta, Góngora, racionero del cabildo; un humanista, Bernardo de Aldrete, canónigo de la misma colegiata, y Garcilaso Inca de la Vega, príncipe

dió por legítimas las interpolaciones de Ulloa y acusó a Mexía de robo descarado; a propósito de los ensayos sobre las edades del hombre, observa: "il ne suffit point qu'il cite en marge les mêmes témoignages que Guevara, pour que le plagiat disparaisse". La carta xxI de Ulloa corresponde a la parte I, caps. I y i de Mexía; la XXII, a su I, XLII, y la XXIII a su II, XxxIv. Es de notar que los cuatro discursos sobre las edades del hombre siguen inmediatamente a la carta xxm, y así el material prestado queda ingeniosamente reducido a un bloque compacto.

${ }_{15}$ Thomas C. Izard, The principal source for Marlowe's "Tamburlaine", $M L N$, LVIII, I943, págs. 4 I I-4I 7 .

${ }_{16}$ The English myrror. A regard wherein al estates may behold the conquests of enuy: containing ruine of common weales, murther of princes, cause of heresies and in all ages spoile of deuine and humane blessings, London, I. Windet for G. Seton, ${ }_{15} 86$. 